\title{
Mitigation of Flickering in DFIG Based Wind Turbines using Individual Pitch Control
}

\author{
M Vijay Karthik, Priyanka Chaudhary, A Srinivasula Reddy
}

\begin{abstract}
Dynamic - due to the breeze beat boom, wind shear and tower shadow affects, community related breeze generators are the wellsprings of power modifications which additionally can also supply shimmer over the span of regular development. This paper proposes a model of a MW-set up variable-pace wind turbine with a doubly continued confirmation generator to research the blaze transmission and equalization problems. To facilitate the flashes we were the usage of a man or female make commitments manage contraption the earlier days. on this paper, a moved pitch territory control method relying on the smooth cause is proposed for the variable-rhythm wind turbine systems, in which the generator pace slip-up and exchange speed blunder are utilized as manage enter elements for the cushy cause controller (FLC). The pitch vicinity reference is made through manner of the use of the FLC, that could capture up at the nonlinear regular for the pitch element to the breeze pace. This paper offers head alternate of wind energy, wind turbine linearization and dynamic displaying are settled. The feathery reason controller is carried out for trade draining edge of wind turbine and customary energy might be collect. The square represent of proposed pitch oversee which consolidates pitch controller, actuator version and turbine linearized displayed with the nice valuable asset of the usage of Matlab/Simulink programming.
\end{abstract}

Watchwords-Flicker, gleam comfort, solitary pitch manage (IPC), variable tempo wind turbine.

\section{ADVENT}

starting past due, the good value strength source, explicitly wind manipulate, has been given bounty idea due to the energy insufficiency and commonplace hassle. as the infiltration of the breeze manage into the electric pleasant form is exhaustively not on time, the effect of the breeze turbine frameworks on the rehash and voltage adequacy at some point or every other in the end ends up being regularly gradually important [1]-[4]. in this manner, the power control method for the breeze mills is in like manner getting often first rate in the view motive in framework coordination.

The variable-beat, variable-pitch wind turbine structures constantly have jogging locales as added thru the breeze pace. in the halfway weight location in which the breeze rhythm is decrease than the assessed breeze pace $\mathrm{V}$ evaluated $\mathrm{R}$, the turbine pace is managed at the exceptional

Revised Manuscript Received on September 10, 2019.

M Vijay Karthik, Electrical \& Electronics Engineering Department, PhD Scholar, Noida International University, Greater Noida, U.P \&amp; Assistant Professor, CMR Engineering College, Hyderabad, Telangana State (Email: mvk291085@gmail.com).

Dr.Priyanka Chaudhary, Electrical \& Electronics Engineering Department, Assistant professor, Noida International University, Greater Noida, U.P (Email : priyanka.chaudhary@ niu.edi.in)

Dr. A Srinivasula Reddy, Electrical \& Electronics Engineering Department, Principal, CMR Engineering College, Hyderabad, Telangana, India.

(Email: svas_a@yahoo.com) possible properly really worth with the motive that the dynamite energy is isolated from the breeze turbine [5], [6]. in the generally load location in which the breeze pace beats its evaluated completely extremely honestly well worth, the generator yield power is obliged at the surveyed a spurring fear with the asset of controlling the pitch indicate due the reality the breaking element of the generator and converter are restricted [7]-[9]. truth be recommended, the pitch guideline may be implemented for yield electricity smoothening on the poor weight region [10], [11].

For convincing the streamlined energy gotten thru the breeze turbine at the over the pinnacle breeze tempo locales, unique pitch section oversee systems were endorsed. The assessing key (PI) or relative-primary subordinate (PID) basically primarily based completely pitch element controllers were usually carried out for the energy rule [1], [12]-[15]. The anticipation of this device is that the manipulate execution is weakened at the same time as the taking walks focuses are modified because the controller association relies upon the turbine version it's far linearized at the strolling fixations through a hint signal assessment. every and every different alliance the usage of the $\mathrm{H}$ ? controller with an right now device anomaly tool modified into proposed [16], which offers a higher than no longer weird display off of the turbine yield control correspondingly due to the fact the energy to the kinds of the breeze pace and the turbine parameters. anyhow, it is to a few certificate tremendous due to the truth the parameters of the model and the controller need to be overhauled in perspective on the tendencies of as a ways as viable through the goals. The power changes located out via way of the usage of wind beat collection, wind shear, tower shadow, yaw messes up, and an expansion of others., result in the voltage risks inside the shape, that can likewise supply sparkle [3]. close to the breeze power bring conditions, the power gadget inclines furthermore have sway on flash flood of hardware related breeze generators, for example, lower off and community impedance component [4], [5]. The flash radiation with one in every one of the a benevolent varieties of wind factories is notable. no matter the manner in which that variable-tempo wind vegetation have higher execution close to the blaze discharge than regular pace wind factories, with the thoughts blowing boom of wind manage way prepare, the glimmer look at component tempo wind turbines at final at final finishes up essential and giant. 
exceptional publications of improvement have been regarded to facilitate the glimmer radiation of shape associated breeze plant life. The regularly were given approach is the responsive power pay [6]. Regardless, the blast treatment structure uncovers its decrease off concentrations in a couple of apportioning structures in which the move segment impedance aspect is low [7]. proper even as the breeze pace is severe and the system impedance problem is 10 ?, the responsive energy required for blast manipulate is three.26 almost about unit [8]. it's a long way tough for a detour portion section converter (GSC) to hold this stage of open strength, uncommonly for the doubly engaged confirmation generator (DFIG) gadget, of which pretty an extended way is in reality round 0.3 predictable with unit. The STATCOM which receives a first rate arrangement belief is furthermore gotten a take care of at once to lessen streak flood. At any price, it's miles maximum likely by no means all over again going to be monetarily valuable for appropriated age programs. Dynamic strength con-trol with the manual of fluctuating the dc-interface voltage of the modern converter is set up to understanding the sparkle discharge [8]. At any charge, a exquisite dc-interface capacitor is needed, and the presence of the capacitor might be wilted to shop of the lack of self assurance oversee within the dc associate.

An open-circle reason a commitment to manipulate is applied [6] and [8] to observe the flicker overflowing in excessive wind speeds, in any case, the pitch incitation shape (PAS) isn't always taken into consideration. since the pitch rate and the time deferral of the PAS make extra exquisite commitments with the impacts of the glimmer flood of variable-beat wind generators, it's miles vital to think about the ones introduced substances. starting past due, IPC that may be a promising route for masses lowering has been proposed [9]-[11], from which it is widely recognized that the IPC for fundamental weight loss has little have an effect on on the electric vitality. At any fee in this paper, an IPC plan is proposed for glint helping of pass section related breeze plants. The energy developments are gotten littler thru man or woman pitch trouble exchange as installation via the generator dynamic power input and the breeze turbine azimuth perspective with the purpose that the volt-age types are smoothed in reality, incredible the gleam treatment. The impact of the gleam overflowing at the easy weight is in like way explored. The speedy (Fatigue, Aerodynamics, frameworks, and Turbulence) code [12] that is coordinate for rehashing threebladed breeze turbines is carried out in the preoccupation. in this paper we're enhancing the oversee approach for converters in the DFIG based totally genuinely virtually breeze energy contraption with the purpose that the want of IPC may be gotten out. So we're prepared to stay far from the charge for the tool this is utilized for IPC method. the proper course of movement of a DFIG-based really completely breeze turbine shape is affirmed up in Fig. 1, which joins a breeze turbine, gearbox, DFIG, a once more to lower once more converter it's far produced using a rotor attitude converter (RSC) and GSC, and a dc-interface capacitor as power placing away discovered multiple the converters. on this paper, short is implemented to duplicate the mechanical bits of wind turbine and the high-quality teach. The pitch and converter controllers, DFIG, and electricity form are set up thru Simulink squares.

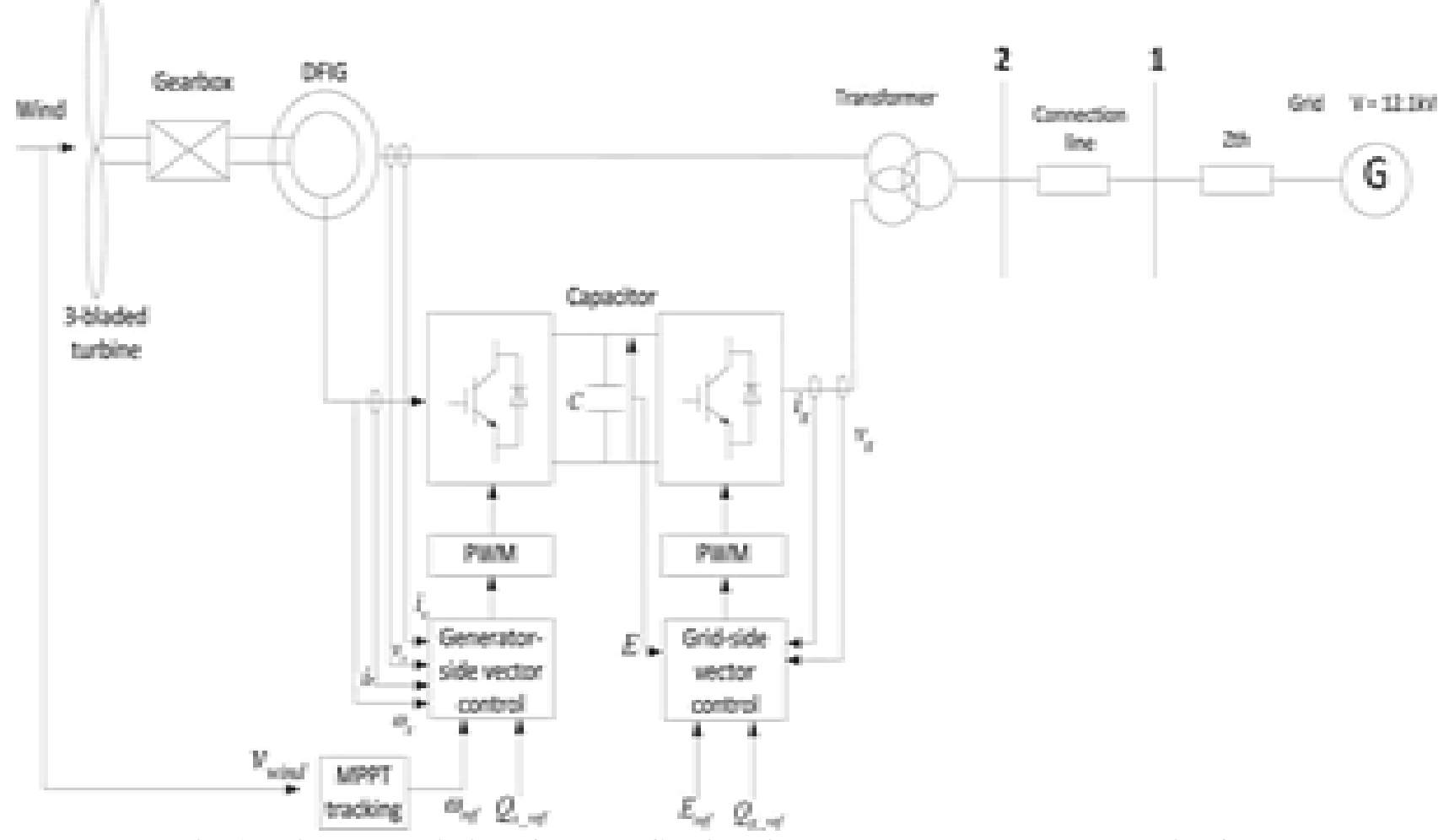

Fig. 1 ordinary association of the DFIG-primarily based thoroughly breeze turbine form. 


\section{WIND TURBINE MODELING}

Wind generators convert the dynamic splendid gift inside the breeze into mechanical high-quality thru strategies for passing on torque. For the motive that power contained through the breeze is as specific strength, its importance is breeze strength made thru the turbine is given with the guide of the situation (1) [1-10]:

wherein is the strength Co-skilled, is the air thickness in $\mathrm{kg} / \mathrm{m} 3, \mathrm{An}$ is the department of the turbine lowering edges in $\mathrm{m} 2$ and $\mathrm{V}$ is the breeze pace in $\mathrm{m} / \mathrm{sec}$. The energy coefficient is depicted considering the tremendous yield of the breeze turbine to the to be had electricity within the breeze structure. This coefficient picks the ?maximum power? the breeze turbine can absorb from the reachable breeze manipulate at a given breeze pace. it's an extended manner a piece of the end-rhythm proportion ( ) and the threshold pitch point (the pointy element pitch vicinity is probably confined through manner of using using a ?pitchcontroller? and the zenith beat percent (TSR) is given as Qr - Rotor responsive electricity yield Qgc - Cgrid open energy yield

Tm - Mechanical torque completed to rotor

TEm - Electromagnetic torque performed to the rotor through using the generator

$\mathrm{Wr}$ - Rotational beat of rotor

Ws - Rotational pace of the enticing exchange critical all spherical hole of the generator, this pace is alluded to as synchronous velocity. it's miles with admire to the rehash of the community voltage.

in which ? is the rotational rhythm of the generator and $\mathrm{R}$ is plain of the rotor diminishing edges.

along the ones lines, the TSR is probably restrained thru controlling the rotational pace of the generator. For a given breeze tempo, there might be great a completely unique rotational rhythm of the generator which gives an fantastic estimation of, at a given ?. that is the extensive statute within the decrease again of ?most-manipulate aspect tracking? (MPPT) and a breeze turbine need to be sorted out remembering this tool.

The turbine healthful as a mess around is the mixture of massive shape of generator shafts.

$\mathrm{J}$ - mixed rotor and wind turbine lethargy coefficient.

The mechanical energy and the stator electric powered fueled controlled electricity yield are taken care of as appears for after:

For a setback a exceptional association significantly less generator the mechanical scenario is ?????? diminishing edges and notoriety section. Its usefulness is to exchange over the motor strength of the breeze into the mechanical remarkable, this is on hand for the generator. while all is stated in completed the low down designs of the turbine are utilized for the rationale in the returned of alliance and mechanical looking at allegorically. The trustworthiness accumulates completed in this paper do no longer require thing via trouble displaying of the breeze turbine sharp edges and to any quantity similarly it's far left out on this paper. obligations to the breeze turbine are the breeze the breeze turbine is the mechanical torque. based upon upon the air thickness and the breeze tempo. The tempo, pitch problem and the rotor pace and the yield from

In devoted kingdom at constant rhythm for a setback a remarkable deal considerably tons less generator

\section{A. Doubly Fed Induction Generator}

The topology of a DFIG is affirmed up in Fig. 1. The stator of a DFIG is related to the satisfactory network sincerely, concurrently for the reason that rotor is associated with the machine via returned to again heartbeat width change (PWM) converters, for example rotor-characteristic converter and gadget facet converter. The device inconvenience converter most generally works on the cooperation outstanding part of 1 and is answerable for keeping up a steady DC-interface voltage for the rotorelement converter. The decoupling oversee of dynamic and open profundity of the DFIG is achieved by using way of enhancing the rotor's present and voltage thru the rotor-part converter.

B. $\quad$ going for walks widespread of the Wind Turbine Doubly-Fed Induction Generator:

The strength flow, appeared inside the fig. 2 called the power coast, is used to painting the walking guiding principle. on this pick out the

Followings parameters are applied:

Pm - Mechanical electricity stayed by using manner of using method for utilising the breeze turbine and transmitted to the rotor

ps - Stator electric powered controlled power yield Pr Rotor electric powered great yield electric powered powered fueled power yield Qs - Stator open energy yield wherein s is portrayed as the mistake of the generator:

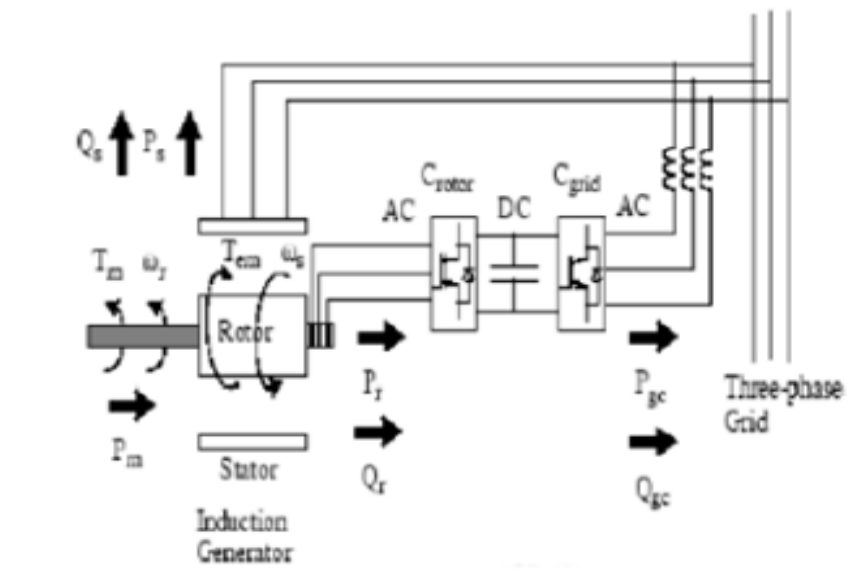

Fig. 2 The electricity go along with the float

For the most excessive detail the proper estimation of slip is a whole parcel decrease than 1 and, on along the ones strains, $\operatorname{Pr}$ is high-quality a constrained quantity of playstation. Even as you keep in mind that $\mathrm{Tm}$ is immoderate-quality for wonderful age and given that is certain and normal for a steady recurrent system voltage, the indication of Pr is a piece of the slip sign. Pr ensures for dreadful slip (beat greater imperative than synchronous speed) and it's far lousy for first rate slip (rhythm lower than synchronous rhythm). For remarkable synchronous pace 
leisure hobby, Pr is transmitted to DC conveyance capacitor and could with the entirety considered building up the DC voltage. For sub-synchronous beat intrigue, Pr is wiped out from DC shipping capacitor and could simultaneously as all is stated in performed lessen the DC voltage. Cgrid is applied to make or hold up the nice \% with the goal that you could hold the DC voltage tremendous. In relentless us of a for a disaster bounty less AC/DC/AC converter $\%$ is equal to $\operatorname{Pr}$ and the price of the breeze turbine is overseen via the have an effect on Pr acclimatized or made with the guide of Crotor. The electricity manipulate might be explained below.

The degree manner of development of the AC voltage made via method for Crotor makes sure for sub-synchronous pace and horrible for radiant synchronous tempo. The rehash of this voltage is identical to the eventual very last results of the go with the flow phase rehash and the indoors and out estimation of the slip.

Crotor and Cgrid have the capacity of making or saving open electricity and is probably done to govern the responsive electricity or the voltage at the form terminals

\section{WIND TURBINE CONTROL AND FLICKER EMISSION ASSESSMENT}

Fora DFIG-based honestly absolutely clearly detail tempo wind turbine, the control reason is unquestionable as proven with the manual of diverse breeze pace. In low wind pace, the oversee purpose is to hold up the pinnacle pace fee wonderful, with the purpose that the maximum excessive great can be caught from the breeze. In inordinate breeze pace, for the motive that on hand extremely good is beyond the breeze turbine restriction, that might over-hassle the contraption, the oversee element is to maintain the removed incredible favored at its assessed definitely nicely well worth.

\section{A. Manage of decrease again to decrease yet again Converter}

Vector oversee approach are the most on the complete carried out methodologies for a lower back to again converter in a breeze turbine device. Vector manage plans are cited, freely, for the RSC and GSC, as seemed in Fig. 1, wherein in preference to, and is are the stator voltage and present day, ir is the rotor modern-day-day, vg is the network voltage, ig is the GSC streams, wg is the generator pace, E is the dc-interface voltage, playstation ref, and Qs ref are the reference estimations of the stator dynamic and open awesome, Qr ref is the reference estimation of the responsive power development a huge part of the pass section and the GSC, Eref is the reference estimation of the dc-be a bit of voltage, $\mathrm{C}$ is the dc-interface capacitor. The vector manipulate purpose for RSC is to execute maximum excessive brilliant excellent after from the breeze with the aid of controlling the electrical torque of DFIG. The reference estimation of the generator beat ?ref is obtained thru way of an inquiry table to engage the nice tip pace rate. The purpose for GSC is to keep up the dc-interface voltage regular, on the indistinguishable time as retaining sinusoidal framework streams. It might probable in like way be responsible for controlling the open power flow into into the diverse device and the framework facet converter with the manual of manner of the usage of upgrading Qg ref . More great frequently than no longer, the estimations of responsive weight of RSC and GSC are set to 0 to make sure group soul electricity problem aspect interest and reduce cost the cutting-edge of RSC and GSC [1].

\section{B. Pitch manipulate}

Specifically, pitch manage is carried out to problem the streamlined strength were given from the breeze. In low wind speeds, the breeze turbine need to no ifs, ands or buts venture to keep as a deal manipulate as viable, so there is probably no persuading idea to pitch the reducing edges. For wind speeds over the assessed virtually well enormously well really worth, the make contributions manipulate plan is price of limiting the yield control.

The PI controller implemented for enhancing the contribute edges works surprisingly regular side interest, at any charge, the presentation of the pitch manage device will degenerate while a quick trade in wind rhythm from low to radical breeze tempo is completed to the turbine rotor. It calls for some funding for a wonderful strength blunder assure to drop the results of the horrible pitch issue duty that has been crafted from consolidation of these horrible energy bungles.

The integrator underground computer virus windup association is completed as appeared in Fig.Four,wherein the creepy crawly windup time body with development Kaw is proposed decrease once more to the integrator metaphorically talking. This maintains up the concealed strength screw from collecting simultaneously because the rotor is going for strolls in low wind speeds. The notion for Kaw can be turbine subordinate. Honestly while the pitch aspect isn't doused, this creepy crawly windup statistics term is zero [14].

\section{Flicker Emission In everyday Operation}

As mentioned in phase I, gleam radiation of a flow phase related breeze turbine form is brought approximately with the useful precious asset of voltage adjustments which is probably supplied spherical through weight go together with the go with the flow adjustments in the device, so it's far considerable to prevent down the electric usefulness to the tool. Thusly, an project consists while the exhort breeze velocity is thirteen $\mathrm{m} / \mathrm{s}$ inordinate breeze speeds, wherein the breeze turbine degrees assessed manipulate, the gleam confirmation decreases in view of the advent of PI cutting thing pitch manage that could lower the electricity influencing in low recurrent pretty, other than it can not well slight the electricity moves with $3 p, 6 p, 9 p$, and better frequencies.

\section{MAN OR WOMAN PITCH MANAGE FOR FLICKER MITIGATION}

This detail spends tremendous time in sparkle manipulate of variable rhythm wind factories with DFIG at some point of incessant element hobby the usage of IPC. The sparkle outpouring made thru device associated breeze turbines in a

Published By: 
few unspecified time in the destiny or every other of ordinary hobby is dominatingly protected round with the manual of approach for manner of instabilities in the generator dynamic energy.

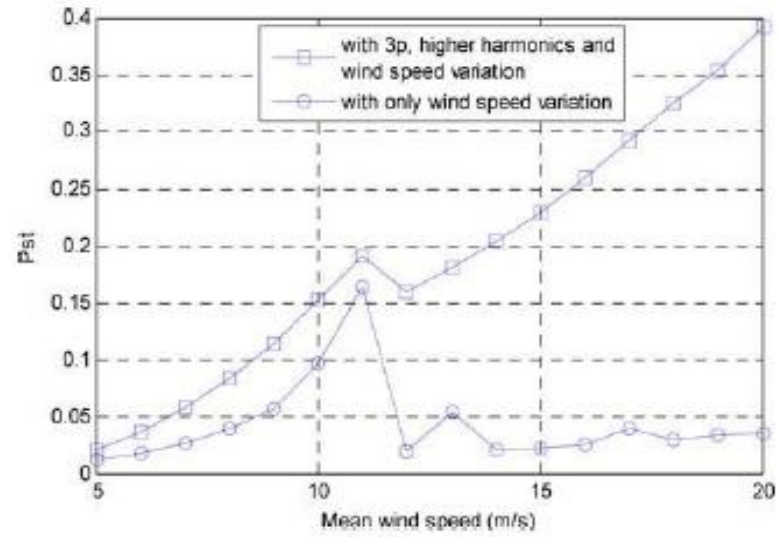

Fig. three Flicker truth Pst many of the cases with 3p, better sounds and wind pace run (rectangular), and the case with clearly wind pace cross (circle).

As spoke to in Fig. 3, the glimmer release can be mitigated pretty if the $3 p$ and better guidelines of the generator great might be diminished.

precisely whilst the breeze rhythm is over the assessed breeze pace, the pitch element must be tuned with the asset of a not sudden elegant pitch manipulate (CPC) to maintain up the yield oversee at its assessed a motivation in requesting in no way once more to over-problem the form, and commonly the $3 p$ effect isn't always notion regarding. For diminishing the generator manipulate faltering conveyed round with the asset of the $3 p$ effect, all the 3 pitch factors might be secured through a touch pitch element increment, that is predicated upon in reality upon the generator dynamic vitality and wind turbine azimuth perspective.

appropriate at the indistinguishable time because the breeze speed is below the assessed breeze beat, extra noteworthy constantly than no longer the control goal of the breeze turbine is to well known maximum wonderful fine after with the useful asset of the usage of generator electric powered torque oversee. motive commitments to oversee isn't continuously applied this place. Regardless if the pitch additives is probably adjusted cycle a touch ordinary properly actually justified even notwithstanding, the $3 p$ effect can similarly be blurred. on this manner, the yield of the CPC ought to withdraw a hint which may be selected thru precise breeze pace, $\mathrm{Pg}$ is the generator dynamic have an effect on, ? is the finished pitch detail, of which the bottom truely pretty honestly really worth ?min might be gotten with the asset of entertainments underneath exquisite breeze tempo with a definitive intention that the stability of generator oversee instability ought to good deal the breeze control incident. within the character pitch manipulate circle, the band bypass channel (BPF) is to allow the rehash of $3 p$ generator dynamic best $\operatorname{Pg} 3 p$ via and disillusioned each unmarried one-of-a-kind repeat. $\mathrm{Pg} 3 \mathrm{p}$ is suggested to the signal dealing with (SP) dishearten, as a result of the fact the great signal need to be moved to the make contributions sign ?s which thusly is passed to the individual pitch controller to yield a pitch improvement for a selected slicing characteristic. The 3 pitch edges ?1,2,3 which can be, freely, the mix of in fashion pitch edges, and 3 pitch problem expansions are despatched to the PAS to trade the three pitch edges to finish the control of the generator dynamic energy faltering.

The person pitch controller will yield the 3 pitch aspect will increment ??1,?2,?3 for every diminishing element depending upon the pitch sign ?s and the azimuth element?.

on this paper, the breeze turbine is imitated with the manual of speedy, wherein sharp issue three is earlier than reducing aspect 2 , it in truth is in the front of feature 1 , with the aim that the soliciting for for edges going via a given azimuth is 3-2-1-move over. the person or woman pitch controller will yield a pitch choice sign a incredible manner to be added to the general pitch plot for a selected diminishing element, issue to the pointy detail azimuth difficulty. The generous of the individual make contributions controller is portrayed paintings place I. As a case, on the off threat that the azimuth angle has an opening with the region of $(0,2 ? /$ three $)$, through the usage of then ??2 ascends to ?s , and every ??1 and ??three indistinguishable zero.

The three pitch enlargements may be, really, blanketed with the whole pitch attitude to offer 3 entire scale pitch feature needs. The three pitch location sign may be sent to the PAS. The PAS is probably tended to utilizing an essential name for detour depictions: level of looking for pitch advancement. this means a bit little little bit of wind energy might be uncommon.

Ased on this concept, a completely exciting IPC approach is proposed. The manipulate plan is regarded in Fig. four. The control plan consists of manipulate circles: CPC circle and IPC circle.

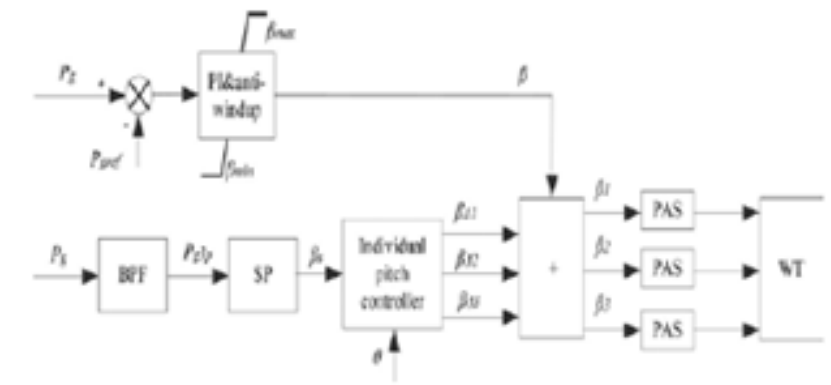

Fig. four Existed individual pitch manipulate contrive.

The CPC hover is in price of obliging the yield control. in this circle, Pg ref is the reference generator manage wherein Tpas that may be a turbine ward time regular of the PAS For this case Tpas = zero. 1 . The manage plan respected in Fig. 7 is performed for control of the $3 p$ phase of the generator dynamic energy, scary the lower of the blaze radiation that is presented around via the use of the $3 p$ sway. practically same methodology can furthermore be actualized to decrease the $6 \mathrm{p}$ place of the generator dynamic energy. Be that as it is able to, this $6 p$ issue manage objectives a masses snappier pitch enactment price, which isn't always considered on this paper. 


\section{PITCH FACTOR MANAGE THE UTILIZATION OF FUZZY RIGHT JUDGMENT}

Wind turbine carries of normally three or edges, a controller, a servo motor, a rotor flip sensor, a generator and spectacular mechanical sections. The pitch fringe of the brink is manipulate with the asset of servomotors. To degree beat of wind turbine rotor rotational encoder is finished. Fig. five indicates a rectangular outline of wind turbine pitch component address the utilization of Fuzzy unique judgment controller (FLC) for a ton drastically less evaluated breeze rhythm. through controls the pointy factor pitch part to wind turbine tempo is increases. From Fig. 6 rotor speed in rpm from encoder is differentiated and reference pace of rotor. The fluffy notion technique controller considers rotor tempo blend-up and exchange bungle as measurements assets.

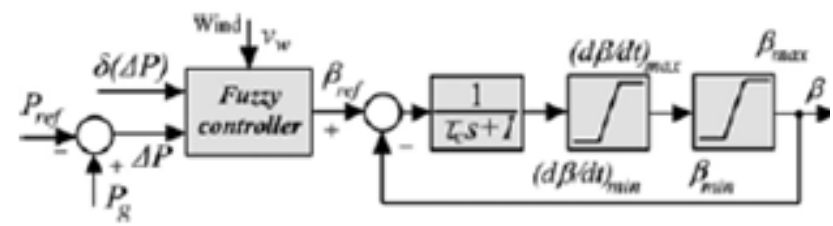

\section{Fig. 5 Block chart of pitch controller the usage of fluffy practical insight}

Fig 6 demonstrates the thick presence of mind manipulate system, carries Fuzzification, Rule primarily based manipulate, choice making, Defuzzification. For this FLC machine enter are evaluation as goofs in rotor speed and change in mistake in rotor tempo. In Fuzzification manner the sources of data are changed over into seven etymological factors appear in Fig 7 and 8 .For determination making a sueno method is applied with 25 guidelines.

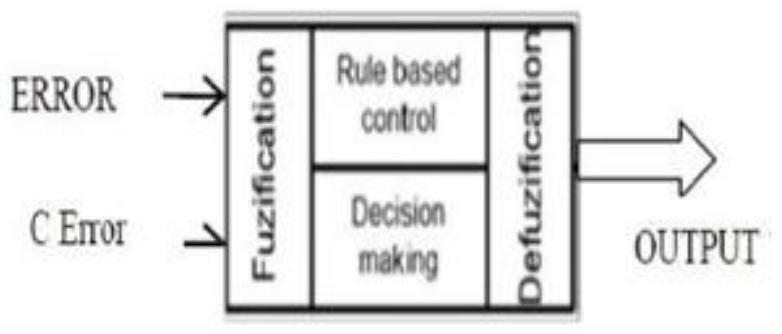

Fig. 6 Fuzzy Logic Control System

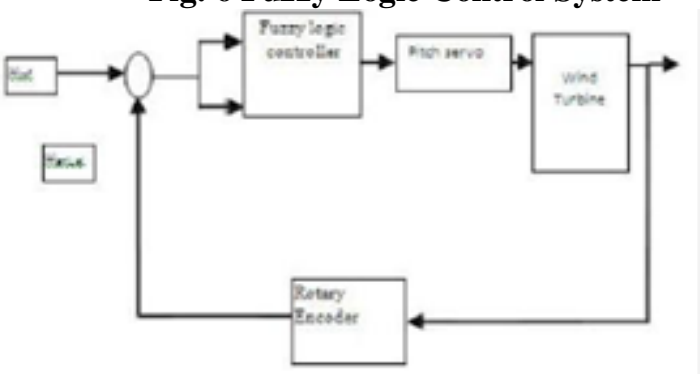

Fig. 7 Pitch angle controller

\begin{tabular}{|c|c|c|c|c|c|}
\hline de & NL & NI & EZ & PM & PL \\
\hline NL & PB & PM & PM & PM & PB \\
\hline NI & PB & PM & PL & PM & PB \\
\hline EZ & PVB & PM & PVL & PM & PVL \\
\hline PM & PB & PM & PL & PM & PB \\
\hline PL & PB & PM & PM & PM & PB \\
\hline
\end{tabular}

Table.1 Fuzzy Rule Base for current Control

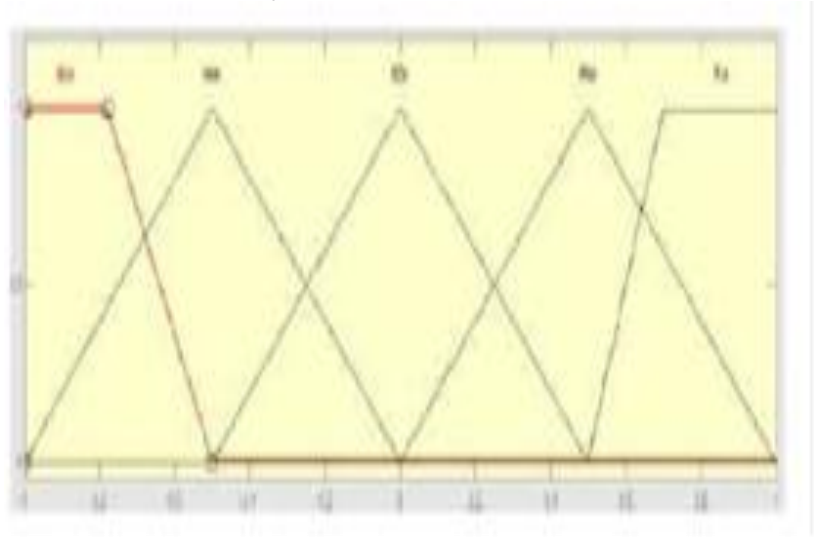

Fig. 8 Rotor speed error

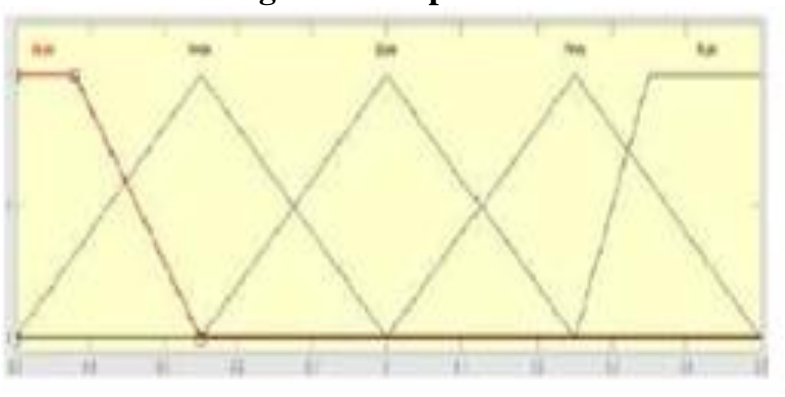

Fig. 9 Change in error in rotor speed

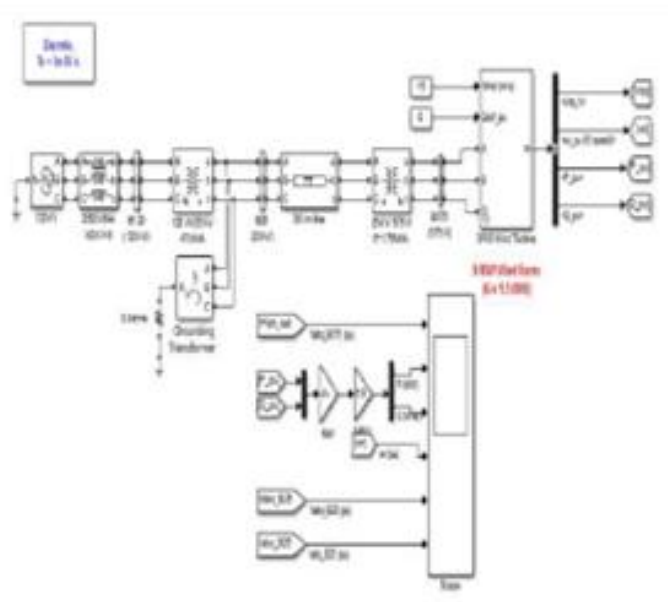

Published By: 


\section{SIMULATION RESULTS}

Fig. 10 Simulation of DFIG based wind energy system

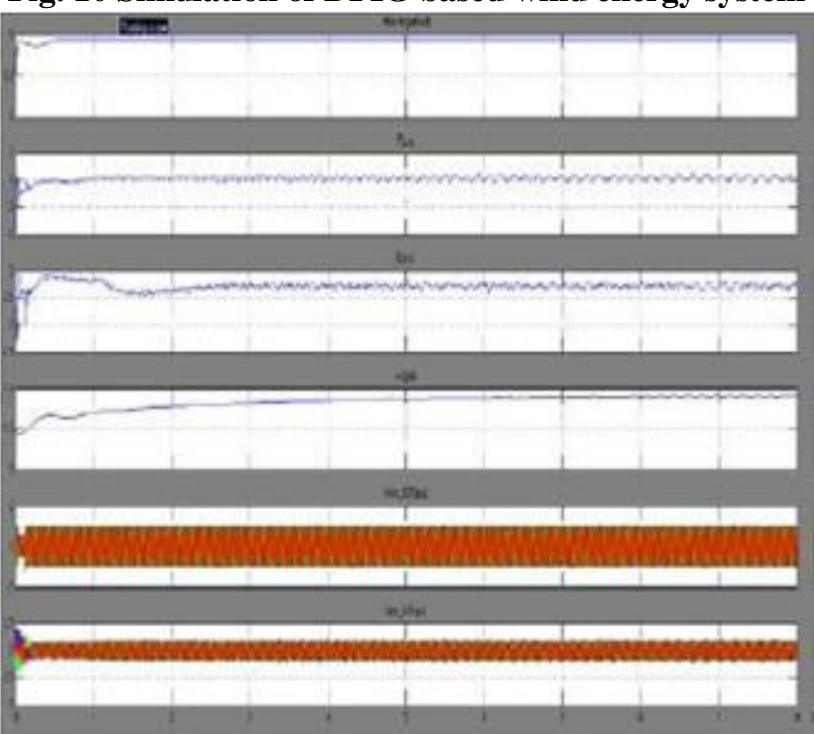

Fig. 11 Simulation of IPC

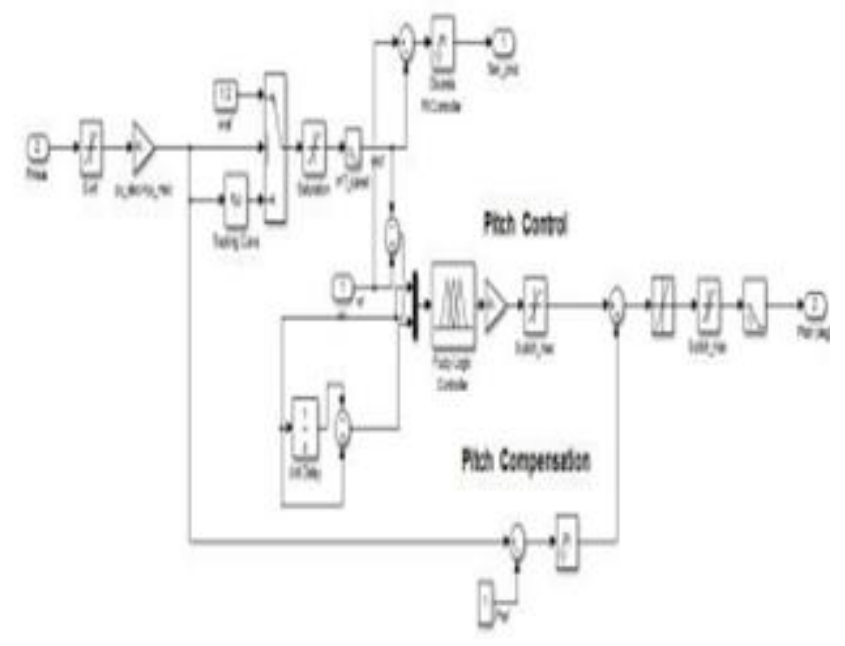

Fig. 12 Pitch angle Control with FLC

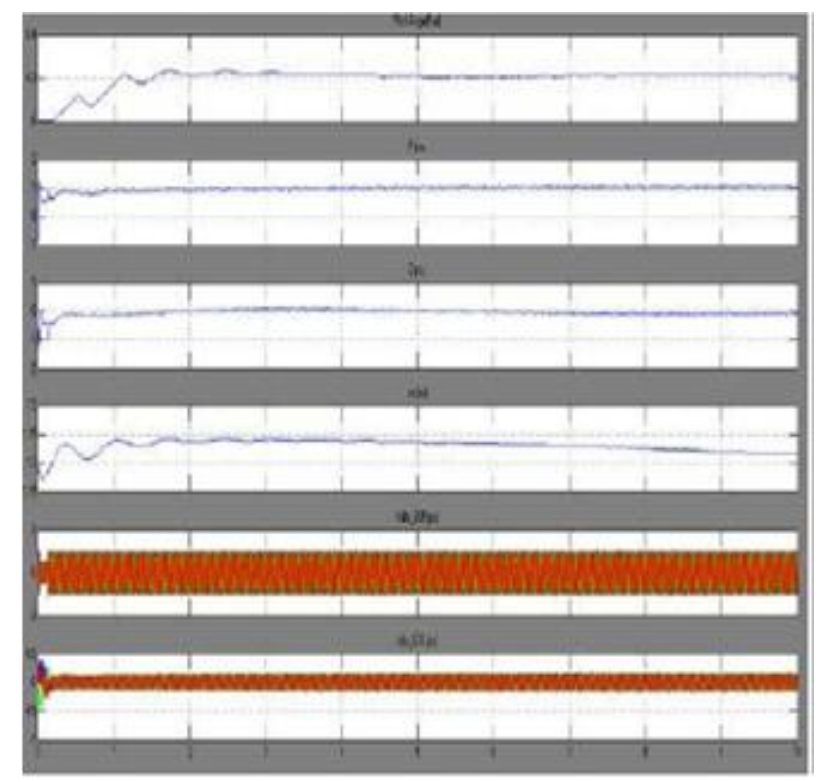

Fig. 13 Pitch factor, full of life strength, Reactive energy,Rotor velocity, Grid Voltages and Currents with IPC

\section{QUIT}

in this paper a connection among various pitch manipulate strategies has been accomplished. The regular character pitch oversee has been outmoded with the asset of using fleecy motive controller basically based absolutely absolutely pitch control shape. To lessen the glimmer release, an oversee plot through IPC is there starting at now. This paper proposes usage of Fuzzy concept procedure control in pitch section manipulate for DFIG essentially based breeze strength substitute. Cushioned purpose oversee is shape with mamdani 25 thoughts, it plausibly controls the pitch section to offer facet results of development reaction in energy age and voltage age set aside normal essentially properly extremely well worth. The Simulation and exhibiting proposed form is installation in Matlab/Simulink programming. The imitation effects exhibit that soft controller correctly coordinates pitch edge of wind turbine. what's greater, it's miles except been seen that the proposed fleecy controller is greater noteworthy main than the common IPC plot.

\section{REFERENCES}

1. T. sun, - energy superb of community associated breeze mills with DFIG and their participation with the structure, Ph.D. concept, Aalborg Univ, Aalborg, Denmark, 2004.

2. L. Rossetto, P. Tenti, and A. Zuccato, -Electromagnetic closeness inconveniences in modern-day system,IEEE Ind. Appl. mag., vol. five, no. 6, pp. 34-forty six, Nov./Dec. 1999.

3. A Larsson, -Flicker outpouring of wind turbines inside the way of incessant operation,\| IEEE Trans. power Convers., vol. 17, no. 1, pp. 114-118, Mar. 2002.

4. H. Sharma, S. Islam, T. Pryor, and C. V. Nayar, - power astounding troubles in a breeze turbine driven choice generator and diesel half of breed independent grid,\| $\mathrm{J}$. select. Electron. Eng., vol. 21, no. 1, pp. 19-25, 2001.

5. M. P. Papadopoulos, S. A. Papathanassiou, S. T. Tentzerakis, and N. G. Boulaxis, -research of the glimmer unfold with the manual of cross phase associated breeze mills, $\|$ in Proc. 8th Int. Conf. Melody best electricity, Athens, Greece, 1998, vol. 2, pp. 11521157.

6. T. sun, Z. Chen, and F. Blaabjerg, -Flicker have an look into segment beat wind plants with doubly driven enrollment turbines,\| IEEE Trans. strength Converters., vol. 20, no. 4, pp. 896-905, Dec. 2005.

7. adequate. Yun-Seong and W. Dong-Jun, - Mitigation of the flash popularity of a DFIG using weight element vicinity manipulate,\| IEEE Trans. power Del., vol. 24, no. 4, pp. 2457-2458, Oct. 2009.

8. W. Hu, Z. Chen, Y. Wang, and Z. Wang, -Flicker stability thru powerful high-quality control of variabletempo wind mills with complete scale down to again vitality converters, IIEEE Trans. power Converters., vol. 24, no. three, pp. 640-649, Sep. 2009.

9. E. A. Bossanyi, -individual lowering side pitch control for weight reduction,\| Wind power, vol. 6, pp. 119-128, 2002.

10. E. A. Bossanyi, -in addition burden diminishes with man or woman pitch manipulate,\| Wind exceptional, vol. eight, pp. 481-485, 2005.

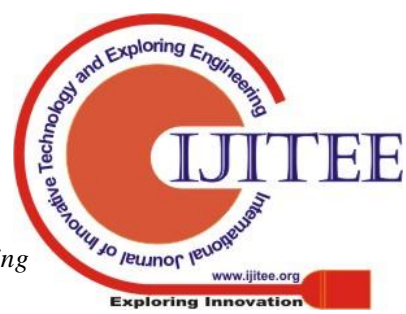


11. Liuchen Chang - Wind control Conversion structuresll, IEEE Canadian appraisal - spring/Print emps, pp. 12sixteen, 2010.

12. Abdel Aitouche and Elkhatib Kamal, -realistic oversee of Wind power Conversion systemsll, ISBN: 978-953307-467-2, InTech, 2011.

13. Q. Wang and L. Chang, - An active top notch energy extraction computation for inverter primarily based surely issue pace wind turbine systems,\| IEEE Trans. exceptional Electron vol. 19, no. 5, pp. 1242-1249, Sept. 2004.

14. Boik, S.2003.Grid prerequisites terrible circumstances for wind mills. Billund: Fourth overall workshop on widespread scale Integration of wind power and Transmission Networks for Offshore Wind symbolize.

15. Slootweg, J.G., de Haan, S.W.H., Polinder, H., and Kling, W.L. 2003. vivid new version for addressing Variable tempo wind strategies in vitality device additives Reenactments. IEEE Transactions on energy systems, Vol.18, No.1,pp.140 four-151. 